\title{
New Application of Chromotropic Acid for the Determination of Some Sulphonamides in their Pharmaceutical Preparations
}

\author{
Fekria M. Abou-Attia ${ }^{1}$, Y.M. Issa ${ }^{2}$, M.A. El Reis ${ }^{1}$, F.A. Aly ${ }^{3}$ and M. Abd El- Moety ${ }^{1}$. \\ ${ }^{1}$ National Organization for Drug Control and Research P.O. Box 29 Cairo, Egypt. \\ ${ }^{2}$ Faculty of Science, Cairo University, Giza, Egypt. \\ ${ }^{3}$ Faculty of Science, Menoufia University, Shebin El-Kom, Egypt.
}

\begin{abstract}
The formation of the azo-dye using chromotropic acid as a coupling agent was applied to the determination of five sulphonamides. The spectrophotometric studies as well as microanalysis of the studied sulphonamides- chromotropic acid azo dyes revealed the existence of the 1:1 coupling product. The absorbance of the formed azo dye is measured at $510 \mathrm{~nm}$, and has a large molar absorptivity $\left(\varepsilon=2.87-3.29 \times 10^{4} 1 \mathrm{~mol}^{-1} \mathrm{~cm}^{-1}\right)$. Beer's law was obeyed over the concentration range $0.5-9.0 \mu \mathrm{g} \mathrm{ml}^{-1}$. The assay results of pharmaceutical formulations showed good accuracy and precision over the concentration range used.

The proposed method avoids time-consumption, extraction process and temperature control.
\end{abstract}

Keywords: Sulphonamides; Chromotropic acid; Azo dyes; Spectrophotometry.

\section{Introduction}

Sulphonamides are widely used in the treatment of urinary tract infections, burn therapy, conjunctivitis and chloroquine resistant malaria. Several procedures have been proposed for the identification and determination of sulphonamide compounds ${ }^{(1-4)}$. Methods of analysis are based upon the properties conferred upon the molecule by the presence of the primary aromatic amino group or the acidic hydrogen in the $-\mathrm{SO}_{2}-\mathrm{NH}$ - group in the molecule ${ }^{(5-8)}$. Current methods for the determination of sulphonamides include titrimetric ${ }^{(9,10)}$, ultraviolet and visible spectrophotometric $^{(11,12)}$ and chromatographic ${ }^{(13)}$ techniques.

The objective of the investigation reported in this paper - was to present a new spectrophotometric method for the determination of some sulphonamides in some pharmaceutical preparations, based on the diazotization of the sulphonamides with sodium nitrite in hydrochloric acid, the diazonium salt was coupled with chromotropic acid

\section{Experimental \\ Reagents}

All reagents were of analytical-reagent grade, water used in this investigation was always twice distilled water. Caution: All the transfers of solutions should be made with an automatic pipette 
Standard nitrite solution (1\%): A $1.0 \mathrm{~g}$ amount of sodium nitrite is dissolved in water and diluted to $100 \mathrm{ml}$ with water in a calibrated flask.

Chromotropic acid (CA) reagent $10^{-2} \mathrm{M}$ : Dissolve $0.4 \mathrm{~g}$ of chromotropic acid (4,5dihydroxynaphthalene-2,7 disulphonic acid disodium salt dihydrate) in water and diluted to $100 \mathrm{ml}$. The solution was stored in a brown bottle in a refrigerator.

Standard sulphonamide solutions $10^{-3} \mathrm{M}$ : Sulphonamides obtained from Elnasr Pharmaceutical Chemicals (Cairo, Egypt), were used to prepare the stock solution by dissolving an appropriate amount of drug in $10 \mathrm{ml}$ of $0.3 \mathrm{M} \mathrm{HCl}$ then diluted to $100 \mathrm{ml}$ with water. Working standard solutions containing $50 \mathrm{\mu gml}^{-1}$ for each sulpha were prepared daily by accurate dilution

\section{Recommended Procedure}

Prepare a calibration curve by transferring volumes containing 25-250 $\mu \mathrm{g}$ of standard sulphonamide solution to $25-\mathrm{ml}$ standard measuring flasks, followed by $0.8 \mathrm{ml}$ of hydrochloric acid $(0.5 \mathrm{M})$ and $0.5 \mathrm{ml}$ of $1 \%$ sodium nitrite solutions. Swirl and allow to stand for $5 \mathrm{~min}$. Add $0.8 \mathrm{ml}$ chromotropic acid (CA), $0.8 \mathrm{ml}$ of sodium carbonate $(6 \%)$ solution, swirl again, dilute to the mark and allow to stand for $15 \mathrm{~min}$. Measure the absorbance against a reagent blank at $510 \mathrm{~nm}$. Plot the absorbance against $\mu \mathrm{g}$ of sulphonamide per $\mathrm{ml}$.

\section{Procedures for Pharmaceutical Preparations}

Tablets: An accurately weighed amount of powdered tablets, equivalent to $100 \mathrm{mg}$ of the sulphonamide was transferred to $100 \mathrm{ml}$ beaker, stirred with $10 \mathrm{ml}$ of $0.3 \mathrm{M} \mathrm{HCl}$ for $5 \mathrm{~min}$, filter the mixture into $100-\mathrm{ml}$ calibrated measuring flask, wash the residue several times with water and dilute to volume with water. Use $2.5 \mathrm{ml}$ of this solution and dilute to $50 \mathrm{ml}$ with water and proceed as given in the general procedure.

Cream: Dissolve accurately $1.429 \mathrm{~g}$ of the cream equivalent to $10 \mathrm{mg}$ sulphadiazine in $5 \mathrm{ml}$ of 0.3 $\mathrm{M} \mathrm{HCl}$, shake for $5 \mathrm{~min}$, filter the mixture to get rid of the precipitated $\mathrm{AgCl}$, wash the residue then dilute the volume with water to $100 \mathrm{ml}$. $50 \mu \mathrm{gml}^{-1}$ solution was prepared then apply general procedure.

Ampoules: A volume of sulphonamide sodium solution, equivalent to $10 \mathrm{mg}$ of sulphadimidine was diluted with $5 \mathrm{ml}$ of $0.3 \mathrm{M} \mathrm{HCl}$ and made up to $100 \mathrm{ml}$ with water in a calibrated flask, $50 \mu \mathrm{g} \mathrm{ml}^{-1}$ was prepared and then subjected to analysis by the recommended procedure.

\section{Apparatus}

A Shimadzu 1601 double -beam spectrophotometer with quartz cells of 1-cm optical path length was used.

\section{Results and discussion}

It has been found that the chromotropic acid azo dyes of sulphonamides absorb maximally at $510 \mathrm{~nm}$ (Fig. 1). The bluish red colour produced from this reaction is thus suggested for the 
colorimetric determination of these drugs. Attempting to obtain the most intense and stable colour, the variables of the experimental conditions were critically investigated as follows:

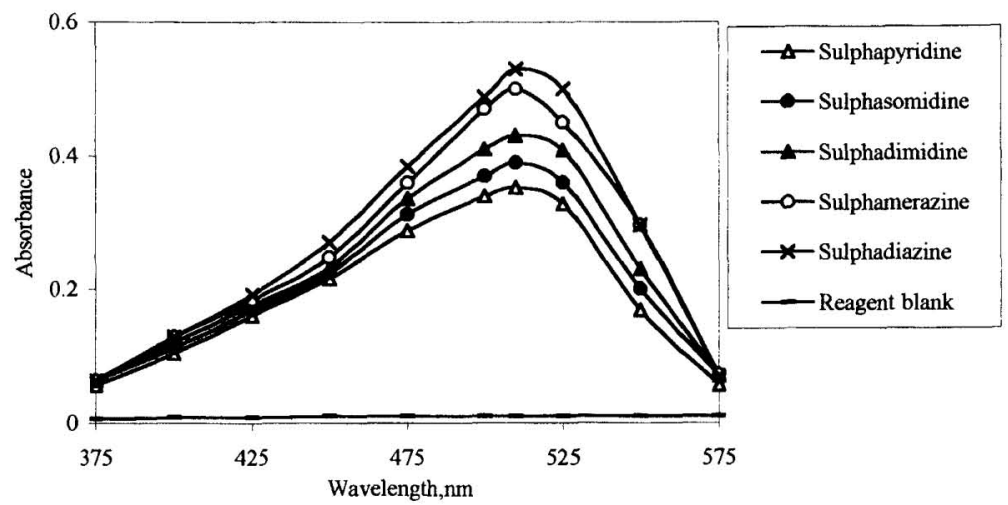

Fig.1. Absorption spectra of sulphonamideazo-CA dyes

\section{Effect of coupling agent concentration:}

When various concentrations of $\mathrm{CA}$ solution were added to a fixed concentration of the sulphonamide, $0.8 \mathrm{ml}$ of $10^{-2} \mathrm{M} \mathrm{CA}$ solution was enough to develop the colour to its full intensity. There was no change in the absorbance at higher concentrations as shown in Fig.(2).

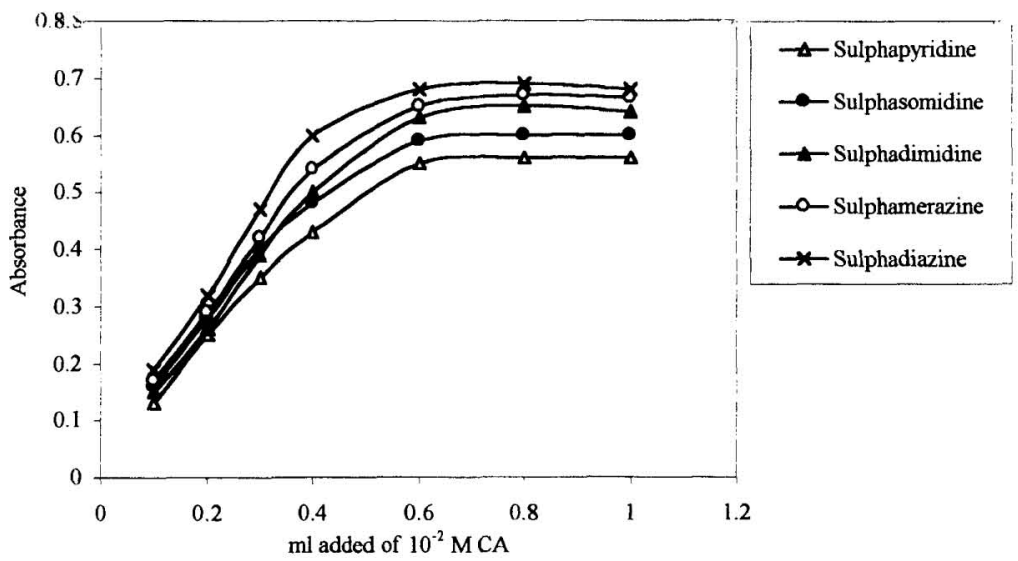

Fig.2. Effect of chromotropic acid cocentration on the determination of sulphonamides, [sulpha] $=2 \times 10-5, \lambda=510 \mathrm{~nm}$. 
Effect of $p H$ :

On investigating the influence of $\mathrm{pH}$ on the formation of sulphonamideazo-CA dye, it is found that the colour of the compound in solution is evidently influenced by the $\mathrm{pH}$. The intensity of the coloured species increase with decrease of $\left[\mathrm{H}^{+}\right]$until a maximum value is reached at $\mathrm{pH}$ 6.87.4 .

Fig.(3) shows that the absorbance of the dye tends to increase with increasing the concentration of sodium carbonate solution until it attains a plateau at $0.5-1.0 \mathrm{ml}$ of $10 \% \mathrm{Na}_{2} \mathrm{CO}_{3}$, corresponding to $\mathrm{pH}$ 6.8-7.4.

The acidity necessary for full colour development was also studied and it was found that the colour started to develop at an acidity of about 0.6 to $0.8 \mathrm{ml}$ of $0.5 \mathrm{M} \mathrm{HCl}$. There was a decrease in absorbance at higher concentrations.

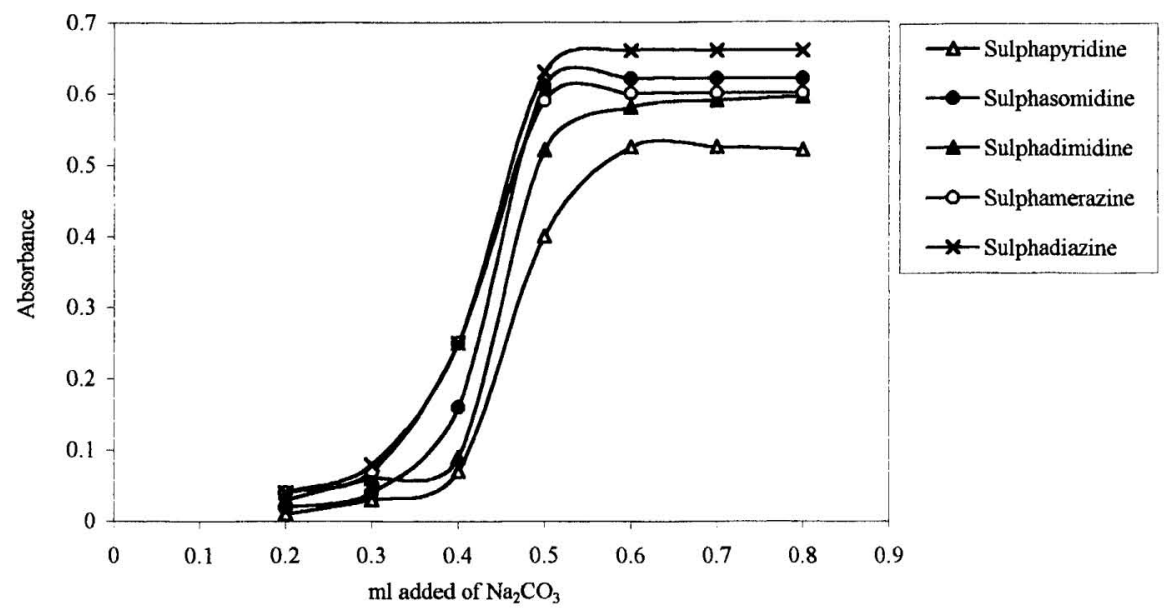

Fig.3. Effect of sodium carbonate concentration on the determination of sulphonamides,

[sulpha $]=2 \times 10-5, \lambda=510 \mathrm{~nm}$.

Effect of temperature and stability of the dye:

The effect of temperature on the colour intensity was studied. It was found that the same absorbance was obtained when the colour was developed either at 20 or $25^{\circ} \mathrm{C}$. Therefore, it is recommended that the reaction is carried out at room temperature.

Under the conditions described above, the reaction mixture has to stand for $25 \mathrm{~min}$ to allow full azo dye formation, after which the colour remains stable for at least $10 \mathrm{~h}$.

Structure of the dyes:

The stoichiometry of the reaction between $\mathrm{CA}$ and the diazonium slat derived from sulphonamides was investigated using the molar ratio ${ }^{(14)}$ and continuous variation ${ }^{(15)}$ methods. The results showed that the dyes have the composition 1:1 (sulphonamide : CA) Indicating mono azo dye. Therefore, the structure of the dye can be written as follows: 


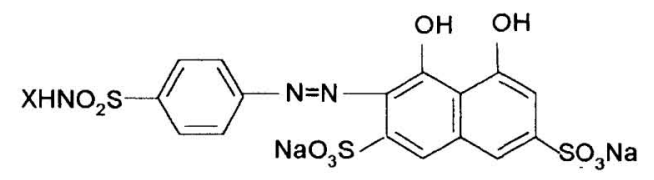

Where $X$ is as follows<smiles>Cc1ccnc(C)n1</smiles>

\section{Sulphadiazine}

Sulphamerazine

III<smiles>Cc1cc(C)nc(C)n1</smiles>

Sulphadimidine
IV<smiles>Cc1cc(C)nc(C)n1</smiles>

Sulphasomidine

V

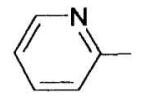

Sulphapyridine

The conditional formation constants of the dyes in aqueous solution under the experimental conditions $\left(\log \mathrm{K}_{\mathrm{f}}\right)$ are within the range 11.09-11.46.

\section{Analytical Parameters:}

Under the experimental conditions described, standard calibration curves for diazotized sulphonamides with CA were constructed by plotting absorbance versus concentration of sulphonamides. Conformity with Beer's law was evident in the concentration range of the final dilution cited in Table (1).

Table(1) Analytical parameters for some sulphonamideazo- Chromotropic acid dyes

\begin{tabular}{|c|c|c|c|c|c|}
\hline \multirow{2}{*}{ Parameters } & \multicolumn{5}{|c|}{ Sulpha } \\
\hline & Diazine & Merazine & Dimidine & Somidine & Pyridine \\
\hline$\lambda_{\max }(\mathrm{nm})$ & 510 & 510 & 510 & 510 & 510 \\
\hline $\begin{array}{l}\text { Beer's law limits } \\
\left(\mu \mathrm{g} \mathrm{ml}^{-1}\right)\end{array}$ & $0.5-7.5$ & $0.5-8.5$ & $0.5-8.5$ & $0.5-9.0$ & $0.5-9.0$ \\
\hline Molar absorptivity $\left(1 \mathrm{~mol}^{-1} \mathrm{~cm}^{-1}\right)$ & $3.15 \times 10^{4}$ & $3.20 \times 10^{4}$ & $3.29 \times 10^{4}$ & $2.96 \times 10^{4}$ & $2.87 \times 10^{4}$ \\
\hline $\begin{array}{l}\text { Sandell sensitivity } \\
\left(\mu \mathrm{g} \mathrm{cm}^{-2}\right)\end{array}$ & $7.95 \times 10^{-3}$ & $8.39 \times 10^{-3}$ & $8.42 \times 10^{-3}$ & $8.83 \times 10^{-3}$ & $9.23 \times 10^{-3}$ \\
\hline Slope (specific absorptivity) & 0.123 & 0.125 & 0.120 & 0.110 & 0.111 \\
\hline Intercepte & 0.009 & -0.032 & 0.002 & 0.006 & -0.007 \\
\hline Corrélation coefficient $(r)$ & 0.9999 & 0.9988 & 0.9998 & 0.9986 & 0.9983 \\
\hline Relative standard déviation $(\mathrm{RSD} \% \mathrm{n}=7$ ) & 0.93 & 1.19 & 0.42 & 1.34 & 1.42 \\
\hline $\begin{array}{l}\text { Ringbom optimum concentration range } \\
\left(\mu \mathrm{g} \mathrm{ml}^{-1}\right)\end{array}$ & $1.41-7.08$ & $1.58-7.08$ & $1.58-7.08$ & $1.58-6.30$ & $1.43-6.31$ \\
\hline $\operatorname{LOD}\left(\mu \mathrm{g} \mathrm{ml}^{-1}\right)$ & 0.15 & 0.19 & 0.07 & 0.24 & 0.13 \\
\hline
\end{tabular}


The molar absorptivity, the Sandell sensitivity and the linear regression equation for each sulpha are listed also in the same Table. The correlation coefficients were 0.9981-0.9999; indicating good

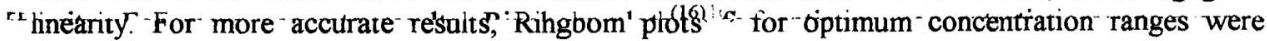
obtained.

Five replicate determinations at different concentration levels were carried out to test the precision of the method (Table 2). The relative standard deviations were less than $1.5 \%$, indicating reasonable repeatability of the selected method.

Table( 2): Tests of precision of the method on pure sulphonamides.

\begin{tabular}{|l|ccccc|}
\hline Sulpha & $\begin{array}{c}\text { Found } \pm \text { SD } \\
\left(\mathbf{u g ~ m l}^{-1}\right)\end{array}$ & $\begin{array}{c}\text { Found } \pm \text { SD } \\
\left(\mathbf{u g ~ m}^{\mathbf{1}}\right)\end{array}$ & $\begin{array}{c}\text { RSD } \\
\%\end{array}$ & $\begin{array}{c}\text { Standard } \\
\text { Error }\end{array}$ & $\begin{array}{c}\text { Confidence Limits } \\
(\mathbf{P}=\mathbf{0 . 0 5})\end{array}$ \\
\hline Diazine & 2 & $2.09 \pm 0.02$ & 0.813 & 0.007 & $2.09 \pm 0.02$ \\
& 4 & $3.93 \pm 0.03$ & 0.611 & 0.011 & $3.93 \pm 0.03$ \\
Dimidine & 6 & $0.15 \pm 0.04$ & 0.618 & 0.017 & $6.15 \pm 0.05$ \\
& 2 & $1.98 \pm 0.03$ & 1.311 & 0.012 & $1.98 \pm 0.05$ \\
& 4 & $4.07 \pm 0.01$ & 0.280 & 0.005 & $4.07 \pm 0.01$ \\
Merazine & 6 & $6.07 \pm 0.02$ & 0.264 & 0.009 & $6.07 \pm 0.03$ \\
& 2 & $1.93 \pm 0.02$ & 1.119 & 0.009 & $1.93 \pm 0.03$ \\
& 4 & $4.08 \pm 0.06$ & 1.470 & 0.027 & $4.08 \pm 0.07$ \\
Pyridine & 6 & $5.94 \pm 0.05$ & 0.842 & 0.022 & $5.94 \pm 0.06$ \\
& 2 & $2.04 \pm 0.02$ & 0.883 & 0.008 & $2.04 \pm 0.02$ \\
& 4 & $3.91 \pm 0.05$ & 1.280 & 0.022 & $3.91 \pm 0.06$ \\
Somidine & 6 & $5.96 \pm 0.07$ & 1.170 & 0.030 & $5.96 \pm 0.09$ \\
& 2 & $2.08 \pm 0.01$ & 0.208 & 0.002 & $2.080 \pm 0.01$ \\
& 4 & $4.13 \pm 0.02$ & 0.426 & 0.008 & $4.13 \pm 0.02$ \\
& 6 & $6.11 \pm 0.02$ & 0.393 & 0.009 & $6.11 \pm 0.03$ \\
\hline
\end{tabular}

$\mathrm{n}=5$

The applicability of the method to the determination of sulphonamides in pharmaceutical preparations was examined. The results are presented in Table (3).

Table (3): Determination of the cited drugs in commercial samples

\begin{tabular}{|l|cccc|}
\hline Sample & Label claim & $\begin{array}{c}\text { Taken } \\
(\boldsymbol{\mu g})\end{array}$ & $\begin{array}{c}\text { \% found } \pm \text { SD } \\
\text { Proposed method }\end{array}$ & USP method $^{(16)}$ \\
\hline Sulphadiazine tablets $^{*}$ & $0.5 \mathrm{~g} / \mathrm{tab}$ & 2 & $98.0 \pm 0.03$ & $99.2 \pm 0.03$ \\
& & 4 & $99.1 \pm 0.05$ & $99.3 \pm 0.09$ \\
& & 6 & $101.5 \pm 0.90$ & $100.5 \pm 0.10$ \\
Argiderm cream $^{\mathrm{b}}$ & $0.7 \mathrm{~g} / 100 \mathrm{~g}$ & 2 & $97.4 \pm 0.04$ & $98.5 \pm 0.10$ \\
(sulphadiazine) & & 4 & $100.6 \pm 0.09$ & $99.9 \pm 0.12$ \\
Sulphadimidine & $33.3 \mathrm{~g} / 100 \mathrm{ml}$ & 6 & $99.9 \pm 0.07$ & $99.7 \pm 0.09$ \\
sodium vial $^{\mathrm{c}}$ & & 4 & $102.0 \pm 0.08$ & $100.0 \pm 0.06$ \\
& & 6 & $98.3 \pm 0.10$ & $97.8 \pm 0.13$ \\
& & $100.9 \pm 0.11$ & $99.5 \pm 0.11$ \\
\hline
\end{tabular}

Standard deviation $(n=5)$

Sulphadiazine tablets contain $0.5 \mathrm{~g}$ per tablet, (EI Nasr Co.)

${ }^{b}$ Argiderm cream each $100 \mathrm{~g}$ contain $1 \mathrm{~g}$ silver sulphadiazine, (Amoun Pharmaceutical Industries Co. (APIC) S.A.E. El Salam City, Cairo, Egypt). 
'Sulphadimidine sodium $33.3 \%$ (vial) for veterinary use, (The Alexandria Co. for

Pharmaceutical and chemical industries, Alexandria, Egypt).

No significant interference is noticed from the excipients commonly used in pharmaceutical preparations. The results obtained are in good agreement with those obtained by the BP and USP $^{(9,10)}$ methods. The proposed method is simple accurate as well as sensitive.

\section{Conclusion}

A simple and sensitive spectrophotometric method for the trace determination of some sulphonamides in aqueous solution has been devised and can be easily used for the routine analysis of drug alone and in the pharmaceutical preparations, and neither temperature control nor solvent extraction is required.

\section{References}

1- Bhushan, R. and Ali, I. (1995), J. Planar. Chromatogr. Mod. TLC. 8: (3), 245

2- Amin, A.S. and Zareh, M.M. (1996), Microchim. Acta. 124: 227

3- Comb, M.T., Ashraf, K. M.,Taylor, LT. and Eujinari, E.M. (1997), Anal. Chem. 69: 3044

4- Yuen, K.H., Peh, K.K., Quah, Y.L. and Chan, K.L. (1997), Drug. Dev. Ind. Pharm. 23: 225

5- Scudi, J.V., (1938), J. Biol. Chem. 122: 539

6- Mellado, R. A., Gomez, B. and Martinez, C. J. (1995), Anal. Chim. Acta. 308: 451

7- Tseng, S.S. and Smith, T.U., (1994), Anal. Lett. 27: 1507

8-Abdel-Gawad, F. M., Issa, Y. M. and Abd- Alhamid, S.M., (1993), Egypt. J. Pharm. Sci. 34: (1-3) 219

9- British Pharmacopoeia, London, (1998), 1: 374

10- United States Pharmacopoeia \&National Formulary, Asian Edition (2000), 1564

11-Banes, D. (1948), J. Assoc. Off. Agric. Chem. 31: 653

12-Hassan, F. A. and Gamal, S. (1991), J. Pharm. Biomed. Anal. 9: (4) 297

13-Simo-Alfonso, E.F. Remiss-Ramose, G., Garcia-Alvarez-Coque, M.C. and Estive-Romero, J.S. (1995), J. Chromatogr. B. Biomed. Appl. 670: (1) 183

14- Job, P., (1995), Ann. Chim. 9: 113

15- Yoe, J. H. and Jones, A. L. (1944), Ind. Eng. Chem., Anal. Edn. 16: 111

16- Ringbom, A. (1939), Z. Anal. Chem. 115: 332 